lower temperature, the former giving rise to minute, positively charged splinters to be blown upwards relative to the larger rime-covered and negatively-charged hail.

On the other were Workman and his colleagues from New Mexico, equally convinced that the charging arises from multitudinous contacts between hailstones and already frozen drops of water. Argument was quickly switched, therefore, to such evidence as there is about the scale of the two different activities and about the milieu in which they occur. The key question which soon emerged was to what extent the thundercloud can accumulate charge of one polarity in one region and of the opposite polarity in another. As Dr. Ross Gunn was to emphasize, full understanding can come only when we have reliable determinations of the nature and the concentrations of the various charge carriers as well as their velocities. Existing evidence is little more than speculation and the difficult task of distinguishing between the two schools (not to mention a third claimant, Dr. Vonnegut, who has propounded a purely convective theory of the thunderstorm) now lies with the meteorologists. At the present time, in the words of Exodus IX, verse 24, we aro left, with "hail, and fire mingled with the hail, very grievous".

On the second major question an important paper was presented by E. C. Whipple, jun., on the electrification between the troposphere and the bottom of the $D$ layer of the ionosphere, a region inaccessible to balloons and difficult to explore from rockets, which disturb the local environment. This is, however, considered the outstanding task for space-vehicles. The day is not far distant when the problems of the dusty atmosphere of Venus and the gigantic atmosphere of Jupiter with its turbulent red spot will present new targets for our ingenuity. In the meantime we have, as an urgent task, to study intensively the language of the radio-emissions from both of them with earth-bound equipment.

A peaceful battle was followed by a feast of informative papers. Many will be stimulated by them. All are worth reading.

BASII SCHONLAND

\section{ABERRATIONS OR REVELATIONS?}

\section{Drugs of Hallucination}

The Uses and Misuses of Lysergic Acid Diethylamide. By Sidney Cohen. Pp. xviii +268 . (London: Secker and Warburg, 1965.) 30s. net.

D R. COHEN, who is a psychiatrist, has written a good, popular account of the hallucinogens, especially lysergic acid diethylamide (LSD), at a cost of less than a penny a page. Drugs of Hallucination is open-minded but not detailed, fair but not neutral. The dangers of therapy with LSD, to therapist as well as patient, are emphasized no less than the enlightenment of "instant Zen". The book describes admirably the terrors as well as the joys of ISD-taking, with the aid of lengthy extracts from subjective accounts. These were, of course, made after the experience had ended: at the time, the subject is relatively (sometimes absolutely) mute, either catatonic or entranced with his jewel-studded umbilicus. It is worth pointing out once again that even those who have enjoyed the experience are invariably dissatisfied with their subsequent attempts to put it on paper. Whatever Mr. Wilson and Mr. Trocehi say, drugs do not help the usor to express himself. They cannot help those who have never written to write at all, and those who are at best indifferent writers continue to write indifferently.

The volume contains an elementary account of hallucinogen chemistry in one appendix, and the sketchiest of phenomenological comparisons of sensory deprivation, psychotic experiences and experiences of LSD in another. There is also an index. What there is notand this is really unforgivable in a book on a serious subject, even if it is intended for a lay audience-is adequate documentation of statements. There are four- teen titles in the bibliography, which are perhaps enough, for the literature on this subject is not of such outstanding quality that it needs to be quoted extensively. Even so, they are not altogether the best titles, nor relevant at all in some cases: and, what is most serious, they contain no mention of his own experimental work; and Dr. Cohen draws on this continually in the body of his book. Since he nowhere in the book describes what he did, to how many, when and with how much (all important matters to the psychopharmacologist), the omission is, to say the least, a nuisance.

Dr. Cohen is a respected and careful scientist, however, whose professional papers can easily be found by reference to the proper sources. This cannot be said for many socalled 'workers' in the field of the hallucinogens, reports of whose activities are all too frequently found in sensational rather than scientific literature. It is an ethical condition of work that the scientist should make his results available in a form that allows any other scientist to attempt to reproduce them, as a preliminary step to building on them. This condition is too seldom met in a field of research that may be as important to the future of mankind as the wheel or nuclear fission. Any tool that may possibly help unravel the torments of our existence is worth close, critical and documented examination.

Most of us are inclined to regard the intellect as the most interesting characteristic of man: but his future development may well depend on deeper understanding and use of his emotions, and research of the best kind into the hallucinogens may be invaluable here. It may be that the effects of LSD are so variable, even in the same individual, because its substrate is the minute-to-minute emotional state of the subject. Such drugs as alcohol or amphetamine are also variable in their effects but these are relatively predictable, perhaps because they depend on mood. If LSD itself works below the level of the intellect, it is all the more important that those who investigate it should not do so as well. As Dr. Cohen points out in his simple but good book, a disturbingly high proportion of those who administer LSD to others go mad themselves! C. R. B. JOYCE

\section{USE AND MISUSE OF LSD 25}

\section{Utopiates}

The Use and Users of LSD 25. By Dr. Richard Blum and associates. Pp. xvi +303 . (London: Tavistock Publications, Ltd., 1965.) 58s. net.

T YSERGIC acid diethylamide (LSD) has been widely 1 used as a research tool in neuropsychopharmacology, and as an adjunct to psychotherapy. It is also, unfortunately, being misused, particularly in the United States, as a drug purveying what has succinctly been called 'instant Zen'. Utopiates: The Use and Users of LSD 25 is a sociological survey of this phenomenon to try to determine who uses the drug in this manner and why. Naturally, the material was not easy to obtain, but Dr. Blum and his co-workers managed to contact ninety-two persons who had taken LSD. These they divided into four groups: (1) an informal professional group, mainly psychiatrists, who had taken the drug outside any recognized research project; (2) a therapy patient sample who had been given LSD by a psychiatrist as part of treatment; (3) an informal black-market sample; (4) the religious-medical centre group associated with an organization (IFIF*) using the LSD experience for a defined religious purpose. These were analysed with respect to a very large number of factors, including type of person involved, their motives, types of reaction obtained, repeated use, proselytizing activity, community attitudes, group interactions, etc. This provides a mine of interesting data on the present-day American scene. The over-all theme appears in the form of earnest attempts by followers of Aldous Huxley to use

- International Federation for Internal Freedom. 